VIVEIROS DE CASTRO, Eduardo. (1986), Araweté: os deuses canibais. Rio de Janeiro, Jorge Zahar.

WAGLEY, Charles. (1988), Lágrimas de boas vindas: os indios Tapirapé do Brasil Central. Belo Horizonte/São Paulo, Itatiaia/Edusp (Reconquista do Brasil, 2. série, vol. 137).

WAGLEY, Charles \& GALVÃO, Eduardo . (1946), "O parentesco tupi-guarani". Boletim do Museu Nacional (Antropologia), 6.

(1961). Os indios Tenetehara: uma cultura em transição. Rio de Janeiro, Serviço de Documentação, Ministério da Educação e Cultura.

WATSON, James B. (1952), "Cayua culture change: a study in acculturation and methodology". American Anthropologist, memoir number 73 , v. 54 (2/2).

JOÃO DAL POZ é professor no Departamento de Antropologia da Universidade Federal de Mato Grosso.

\section{Trabalbadores e indústria automobilística em tempos de reestruturação}

Leila BLASS. De volta ao futuro: o discurso empresarial e sindical no fim da Autolatina. São Paulo, Educ/Cortez/Fapesp, 2001. 194 páginas

Marco Aurélio Santana

Nas últimas duas décadas, o mundo do trabalho brasileiro e seus atores, em consonância com o cenário global, enfrentaram diversos processos de transformação. Passando de um período de abertura política, para outro de abertura econômica, empresários e trabalhadores buscaram, a seu modo, lidar com o que seria "um furacão devastador". Entre outras coisas, os empresários, sempre protegidos pelo fechamento da economia nacional, foram obrigados a uma competição agora em escala global; os trabalhadores, sempre o elo mais fraco, sem o impulso inflacionário para suas manifestações, tendo de enfrentar o desemprego em escala geométrica, trocaram as pautas de conquista salarial e de melhores condições de trabalho pelas pautas de manutenção do emprego. No atacado, o que se viu foi o enxugamento de setores e o fechamento de empresas, a liquidação de postos de trabalho e a relativa diminuição tanto do poder do empresariado industrial (substituído em cena pelo financeiro), como do poder sindical no cenário nacional. Acabou-se o tempo em que a FIESP e a CUT eram figuras recorrentes no Jornal Nacional. Empresas e trabalhadores, evidentemente a partir de seus próprios interesses, tiveram de rever suas estratégias de relação entre si e com o mundo.

De volta ao futuro: o discurso empresarial e sindical no fim da Autolatina, de Leila Blass, fruto de sua tese de livre-docência na PUC-SP (1999), traz uma importante contribuição para o entendimento de uma experiência bastante relevante na história do movimento sindical brasileiro entre os anos de 1980 e 1990, bem como da chamada reestruturação produtiva em nosso país. O livro auxilia tanto o leitor especializado, 
como o de um público mais amplo, a percorrer a trajetória de uma parte importante do operariado nacional e das empresas a ele vinculadas. Embora parta de um caso específico, a Autolatina, constituída a partir da fusão da Ford e da Volkswagen (VW), o trabalho cria possibilidades para a reflexão comparativa com outras trajetórias e exemplos.

Além de se basear em documentação produzida no âmbito empresarial e sindical, a autora utiliza a história oral, produzindo um quadro enriquecido por relatos e pela representação dos atores envolvidos no processo. Esse procedimento, mais do que uma mera opção metodológica, insere-se em uma orientação teórica que acompanha todo o trabalho, a qual vê com ressalvas a aplicação de modelos gerais de análise e interpretação sem as devidas mediações e adequações às particularidades presentes nos casos estudados. Assim como desconfia dos modelos políticos e econômicos que estão sempre em busca (ou em defesa) da chamada "racionalidade econômica" pura, a qual, desconhecendo sua inserção social, supostamente transcenderia contextos nacionais e locais, devendo ser aplicada como panacéia geral.

Dessa forma, Leila Blass tenta apontar "as nuanças que perpassam as idéias de mundialização e globalização, ressaltando a importância dos localismos e não exclusivamente da globalização e seus efeitos" (p. 23). Na mesma linha, indica que:

Nenhum processo social, inclusive a chamada reestruturação produtiva, pauta-se, portanto, pela homogeneidade, nem segue uma evolução linear predefinida. [...] A implementação dos projetos dependem, desse ponto de vista, do jogo interno entre as forças sociais e políticas presentes em um determinado momento histórico. As propostas emergentes na sociedade viabilizam-se pela ação dos diferentes atores sociais presentes na cena pública, como seus porta-vozes ou opositores (p. 31).

Partindo de tal orientação, o trabalho, dividido em uma introdução (teórico-metodológica) e dois capítulos, tem como objetivo ressaltar "as práticas gerenciais diferenciadas da Ford e da VW ante os funcionários e o sindicato" e a reconstituição "da trajetória sindical e operária dos metalúr- gicos da região do $\mathrm{ABC}$ paulista” (p. 34), bem como de seu papel na formação da proposta conhecida por reestruturação negociada. Além disso, o texto busca "enfatizar que as formas de gestão do trabalho e da produção, sejam elas fordistas, pós-fordistas, produção enxuta ou incluídas sob a denominação geral de 'métodos japoneses de gestão', são sempre híbridas" (p. 35).

No primeiro capítulo, temos a análise do processo de fusão e des-fusão da Autolatina, seus impactos e conseqüências. No ano de 1987, a empresa norte-americana Ford e a alemã VW, optando por uma fusão, criam a Autolatina, o que incluiria suas plantas no Brasil e na Argentina, em uma experiência tentada também em Portugal com a AutoEuropa. Apesar da etapa jurídica cumprida em 1987, será apenas em 1990 que as montadoras iniciam o funcionamento da empresa, que tinha $51 \%$ de suas ações controlados pela VW e $49 \%$ pela Ford.

Há um certo consenso na literatura especializada de que a estratégia de fusão teve a ver com a conjuntura pela qual passava "a indústria automobilística brasileira na segunda metade da década de 80 " (p. 44). Essa estratégia visava a responder tanto à retração de mercado interno, quanto à tímida participação das montadoras brasileiras no mercado internacional. Buscava-se, também, garantir a permanência das duas montadoras no mercado interno, com altas taxas de lucro. Ambas as montadoras vinham de uma crise de vendas e espaço de mercado no início dos anos de 1980. No caso da Ford, parecia mesmo ser a saída para sua permanência no país. Antes da fusão, a VW controlava 34\% do mercado interno brasileiro, já a Ford, mantinha uma fatia de $21 \%$. Após a fusão, passaram a controlar juntas, $60 \%$ do mercado brasileiro e $30 \%$ do argentino.

Em teoria, a fusão adequava-se aos novos tempos como estratégia capitalista global e era pensada como uma saída ideal para as duas montadoras. Porém, o estabelecimento concreto da Autolatina, em seus sete anos de existência, enfrentou sérias dificuldades internas e externas. $\mathrm{O}$ primeiro e grande problema a ser enfrentado foi a falta de investimento das matrizes. Dado a concorrência entre a Ford e a VW, em âmbito mun- 
dial, havia a dificuldade da troca de conhecimento técnico, debilitando as colaborações locais. Outro problema foi a constante tensão entre a Autolatina e os sucessivos governos brasileiros com os quais, por motivos diferentes, ela se desentendeu, ora por causa do congelamento de preços, ora por conta da supervalorização da moeda.

E não foi só com o governo que a Autolatina se desentendeu. Nesse quadro, segundo um de seus diretores, a Autolatina "brigou com o mundo" (p. 54). Leia-se, brigou com o governo, os fornecedores, os revendedores e o sindicato. No caso dos revendedores, como não houve inter-relação processo/produto/mercado, as vendas eram feitas em separado pelas montadoras que, apesar da fusão, continuavam disputando o lançamento de carros novos no mercado, cada uma com sua marca de origem. No que diz respeito às altercações com o sindicato, tanto as plantas da Ford, como as da Volkswagen sofreram paralisações. No caso da Ford, em grande medida essas paralisações tiveram a ver com o "reconhecimento político da representação interna dos trabalhadores e da presença do sindicato no cotidiano das fábricas" (p. 57). Já no caso da VW, "as condições de trabalho [foram] os principais temas abordados nas negociações entre representantes patronais e a comissão de fábrica, provocando muitos protestos por parte dos trabalhadores" (p. 57).

Os problemas da Autolatina com o sindicato não se esgotavam nos conflitos entre a empresa e seus funcionários. Advindas de culturas empresariais bastante distintas, a alemã (paternalista - VW) e a norte-americana (pragmática Ford), e partindo do fato de que mantiveram sua individualidade, não foi fácil para a Autolatina implementar as decisões empresariais cotidianamente. O cruzamento de culturas tão diferenciadas não foi feito sem tensões, sobretudo no que tange à história e à identidade dos atores envolvidos. É por isso que Blass observa constantemente, ao longo de sua pesquisa, que os metalúrgicos sempre se identificavam como sendo trabalhadores de uma das duas montadoras, e nunca como trabalhadores da Autolatina. Nesse sentido, como indica a autora:
Nas fusões de empresas, as tradições culturais e experiências históricas não desaparecem, ao contrário, são reafirmadas. Portanto, o choque entre as diferentes orientações gerenciais pode comprometer os resultados econômicos, pondo em risco a continuidade dos acordos estabelecidos, por mais lucrativos e convenientes que eles sejam do ponto de vista dos negócios (p. 69).

A fusão, acumulando tal gama de problemas, ainda que tenha possibilitado às empresas "superarem os ventos adversos", chega ao fim da linha sem ter produzido "um carro próprio, exceto os caminhões na fábrica Ipiranga, em São Paulo" (p. 51). A "velha" Ford e a "nova" Volkswagen (res)surgiram teoricamente da "des-fusão". Como assinala Leila Blass, "O processo de formação e des-fusão da Autolatina indica que os fatores econômicos não são determinantes na tomada de decisões empresariais, pois elas estão mediadas por várias condições nas quais eficácia econômica detém um peso relativo" (p. 80).

Tendo analisado todo esse processo, a autora, no segundo capítulo, detém-se sobre a trajetória sindical, que vai das jornadas heróicas dos anos de 1980 até o chamado sindicalismo propositivo dos anos de 1990 e de sua participação no processo de transformação do mundo do trabalho, propondo uma reestruturação negociada.

Sem cair em equívoco freqüente em certa literatura, a autora vai tecendo os fios de continuidade entre o sindicalismo que surge no final dos anos de 1970 no ABC (e que, posteriormente, fomentou a criação do Partido dos Trabalhadores e da Central Única dos Trabalhadores) e o sindicalismo do período anterior. Além disso, ao analisar os movimentos reivindicatórios dos trabalhadores metalúrgicos da região, inclui e indica a importância de outros segmentos de trabalhadores que, quase sempre, são excluídos das investigações muito centradas nos operários das montadoras e em sua ação coletiva. Por exemplo, a campanha salarial de 1985, que resultou em uma greve, deixou "claro o papel das pequenas e médias empresas no estabelecimento das negociações com os trabalhadores, tendo em vista a diversidade industrial da região do $\mathrm{ABC}$ paulista onde as autopeças complementam as montadoras em São Bernardo Campo e Diadema" (p. 103). 
Baseando-se no perfil de uma amostra realizada pelo sindicato em 1989, Blass fornece várias informações a respeito da categoria. A partir desses dados, a autora analisa a valorização da profissão pelos metalúrgicos que não se refere ao trabalho em si, porém,

[...] está mediada pelo exercício de uma atividade cotidiana realizada, ano após ano, em uma mesma empresa, criando fortes laços afetivos e pessoais entre trabalhadores e trabalhadoras. Estar empregado, principalmente nas montadoras, seria manter um espaço privilegiado de sociabilidade (p. 109).

Mais ainda:

O sentimento de pertença e de união e a valorização do contato com os colegas nas fábricas foram coletivamente construídos e reconstruídos ao longo da trajetória de vida, podendo ser considerado um resultado "invisível" das inúmeras lutas e embates com o patronato e o Estado, desde os anos 60 e mais particularmente fins dos anos 70 . No calor dos confrontos e impasses políticos, são forjados valores, as crenças, as representações, as expectativas; tradições culturais herdadas são recriadas de rememoradas (p. 109).

Tal capacidade de recriar a tradição possibilitou aos metalúrgicos do $\mathrm{ABC}$ inovarem constantemente suas práticas de mobilização. É assim que podemos ver a prática da greve assumir várias formas diferentes, como a "operação tartaruga", a "vaca brava" e as "golas vermelhas". É também por causa dessa característica que, "diante das mudanças que se vislumbraram no horizonte", os trabalhadores e suas lideranças "tentam dar continuidade à prática sindical e às formas institucionais adaptadas às condições históricas. Nesse momento, elaboram e reelaboram o discurso em torno da reestruturação negociada, fundado nas suas experiências recentes de luta" (p. 109).

A idéia da chegada de um "novo tempo" para o mundo do trabalho e seus atores, vai encontrar ressonância na liderança do $\mathrm{ABC}$, entre outras, já na virada dos anos de 1980. Partia-se da idéia de que, dadas às novas configurações na esfera do trabalho, trazidas seja pela modernização tecnológica, seja pela introdução de novas formas de gerenciamento e organização da produção, os dirigentes e os militantes sindicais deveriam apresentar propostas efetivas para o processo em curso, impedindo que seus resultados fossem prejudiciais aos trabalhadores. Assim, se apropriariam, à sua maneira, imprimindo-lhe seu rosto, "do discurso elaborado em torno do processo de reestruturação produtiva, mudando-o de sinal" (p. 99).

Disputar os cursos da mudança, ainda que não garantisse uma vitória integral dos trabalhadores, ao menos serviria para limitar os impactos da mesma sobre as condições de vida e trabalho da classe operária. A autora busca, por meio da análise de casos concretos (estrutura salarial horista, na Autolatina, e jornada de trabalho, na Ford e na VW, pós-Autolatina), identificar quais os limites e as possibilidades desse novo ideário compartilhado pelos metalúrgicos do $\mathrm{ABC}$, que, devido à sua influência na parcela mais significativa do movimento sindical brasileiro, não sem intensa polêmica, se espraiou entre lideranças de outros setores e categorias no interior do sindicalismo brasileiro.

Os exemplos demonstram como os trabalhadores podem conquistar espaços importantes quando seus órgãos de representação (sindicato, comissão de fábrica, comissões paritárias) se dispõem a participar, via negociação, dos processos que podem atingir, positiva ou negativamente, a vida dos trabalhadores e, ato contínuo, na sobrevida de seus representantes. Porém, em via de mão dupla, indica também, as possibilidades de que os empresários, de forma instrumental, possam se utilizar dessa participação em interesse próprio, sem contemplar os trabalhadores.

Tal participação em processos de negociação, tendo vindo junto com a relativização do papel das greves em termos de eficácia em ganhos para os trabalhadores, fez com que muitos construíssem uma visão dicotômica, que considera o sindicalismo dos anos de 1980 "combativo", porque fazia greve, e o dos nos de 1990, "negocial", porque não faria greve. Segundo a autora,

[...] as questões em jogo são mais profundas e não se reduzem ao fato de fazer ou não greve, de negociar ou não, de aceitar ou negar a conflitualidade social. O debate deveria abordar também 
o modo de se produzir os conhecimentos científicos, noções e categorias de análise que informam as práticas sindicais e a elaboração de projetos políticos a fim de verificar se são portadores de inovações efetivas ou apenas reproduzem o que já é conhecido (p. 169).

Assim, mais do que buscar qualificar os períodos como positivos e negativos, como já se fez em momentos anteriores, a autora afirma que

[...] contrariando uma certa nostalgia que considera a ação sindical propositiva, o grito de agonia do movimento sindical e operário brasileiro, nesses tempos de globalização, ousaria afirmar [...] que a prática sindical dos metalúrgicos São Bernardo do Campo e Diadema passa por um processo de reformulação (p. 173).

Para Blass, estaríamos testemunhando o fechamento de um ciclo da história operária e sindical do ABC paulista. Nessa mesma linha, afirma que mais do que uma crise produzida por mudanças técnicas e organizacionais, capitaneadas pelo capital, as dificuldades do sindicalismo dizem respeito às "questões de organização interna do movimento operário e sindical brasileiro" (p. 178), como por exemplo, a dificuldade de incorporação dos jovens em suas fileiras.

O estudo de Blass, partindo de uma perspectiva particular, apresenta indicações instigantes e reforça certas visões que podem auxiliar o debate político e acadêmico sobre o tema. Indico aqui três, entre outras, que afloram, direta ou indiretamente, da leitura do texto. Primeiro, que, apesar de todo o discurso reinante, os processos econômicos se dão sempre mediados pelas relações sociais nos contextos onde buscam se estabelecer. Segundo, que devemos romper com as visões dicotômicas da história dos movimentos operário e sindical brasileiros, as quais têm estabelecido apenas rupturas entre os diversos períodos, sempre os dispondo em termos qualificativos e adjetivos, que colocam um, como possuidor de todas as características positivas, e outro, como detentor de todos os problemas do mundo. Terceiro, que a crise pela qual passam as entidades de representação dos trabalhadores não pode ser reduzida a um mero resultado dos avanços do capital sobre elas. Para que se entenda essa crise em profundidade, segundo a autora, é preciso que se perceba que, em muito, ela também é oriunda de formas e orientações político-organizacionais que não só entraram em colapso, como também podem ter mesmo chegado ao esgotamento. Para que continuem sendo relevantes no cenário local e global, os trabalhadores e suas entidades devem, a partir de uma incorporação criativa de suas tradições, recriar suas formas de análise, organização e intervenção na realidade.

MARCO AURÉLIO SANTANA é professor do departamento de Filosofia e Ciências Sociais da Universidade do Rio de Janeiro (UNIRIO) 